\title{
Meglitinides increase the risk of hypoglycemia in diabetic patients with advanced chronic kidney disease: a nationwide, population-based study
}

Pei-Chen $\mathbf{W u}^{1,2, *}$, Vin-Cent $\mathbf{W u}^{3, *}$, Cheng-Jui Lin ${ }^{1,4,5}$, Chi-Feng Pan ${ }^{1}$, Chih-Yang Chen $^{1}$, Tao-Min Huang ${ }^{6}$, Che-Hsiung Wu ${ }^{7}$, Likwang Chen ${ }^{8}$, Chih-Jen $\mathbf{W u}^{1,4,9,10}$ and The NRPB Kidney Consortium ${ }^{11}$

${ }^{1}$ Division of Nephrology, Department of Internal Medicine, Mackay Memorial Hospital, Taipei, Taiwan

${ }^{2}$ Graduate Institute of Clinical Medicine, College of Medicine, National Taiwan University, Taipei, Taiwan

${ }^{3}$ Division of Nephrology, Department of Internal Medicine, National Taiwan University Hospital, Taipei, Taiwan

${ }^{4}$ Department of Medicine, Mackay Medical College, Taipei, Taiwan

${ }^{5}$ Mackay Junior College of Medicine, Nursing and Management, Taipei, Taiwan

${ }^{6}$ Department of Internal Medicine, National Taiwan University Hospital Yun-Lin Branch, Douliou, Taiwan

7 Division of Nephrology, Taipei Buddhist Tzu Chi General Hospital, Buddhist Tzu Chi University, Taipei, Taiwan

${ }^{8}$ Institute of Population Health Sciences, National Health Research Institutes, Zhunan, Taiwan

${ }^{9}$ Graduate Institute of Medical Sciences and Department of Pharmacology, College of Medicine, Taipei Medical University, Taipei, Taiwan

${ }^{10}$ Department of Medical Research, China Medical University Hospital, China Medical University, Taichung, Taiwan

${ }^{11}$ NRPB, National Research Program for Biopharmaceuticals, ROC, Taiwan

* These authors have contributed equally to this work

Correspondence to: Chih-Jen Wu, email: yaliwcj@gmail.com

Keywords: meglitinide, diabetes mellitus, hypoglycemia, chronic kidney disease, mortality

Received: January 21, $2017 \quad$ Accepted: April 14, $2017 \quad$ Published: April 27, 2017

Copyright: Wu et al. This is an open-access article distributed under the terms of the Creative Commons Attribution License 3.0 (CC BY 3.0), which permits unrestricted use, distribution, and reproduction in any medium, provided the original author and source are credited.

\section{ABSTRACT}

The safety of short-acting meglitinides in diabetic patients with advanced chronic kidney disease (CKD) has not been widely reported.

Diabetic patients with advanced CKD who had a serum creatinine level of $>6$ $\mathrm{mg} / \mathrm{dL}$ a hematocrit level of $\leqq \mathbf{2 8} \%$ and received erythropoiesis-stimulating agent treatment between 2000 and 2010, were included in this nationwide study in Taiwan.

The outcomes of interest were defined as hypoglycemia and long-term mortality. The risks of hypoglycemia and death were analyzed using Cox proportional hazards models, with end-stage renal disease and anti-diabetic drugs as time-dependent variables.

Fresh users and matched non-users of meglitinides (both $n=2,793$ ) were analyzed. The use of meglitinides increased the risk of hypoglycemia (HR, 1.94, p $<0.001$ ), as did other anti-diabetic agents. Concomitant use of meglitinide and insuilin will incresase the hypoglycemic risk. $(H R, 1.69, p=0.018)$ Moreover, it was not the use of meglitinides, but the presence of hypoglycemia that predicted mortality. The function curve showed an insignificant trend towards increased hypoglycemic risk in patients aged $>62$ and $\leq \mathbf{3 3}$ years from the generalized additive model.

This study suggests that the use of short-acting meglitinides could be associated with increased risk of hypoglycemia in diabetic patients with advanced CKD, especially in patients aged $>62$ and $\leq 33$ years. Meglitinide combined with insulin will increase hypoglycemia in patients with advanced CKD. 


\section{INTRODUCTION}

Diabetes mellitus is a leading cause of death, cardiovascular disease and microvascular complications [1]. Although tighter glycemic control decreases the risk of certain microvascular damage events such as new-onset albuminuria, its effect on reducing death and macrovascular events remain controversial [24]. Optimal glycemic control is required to minimize diabetes-associated complications and to avoid the risk of treatment-related hypoglycemia. Drugs that lower postprandial glucose without predisposing patients to hypoglycemia appear to control hyperglycemia and improve cardiovascular outcomes [5].

The challenges for improving glycemic control in patients with chronic kidney disease (CKD) include therapeutic inertia, monitoring difficulties, and the complexity of procurable regimens [6]. The incidence of hypoglycemia is also found to be higher among patients with CKD rather than those without [7]. Altered pharmacokinetics of anti-diabetic agents in CKD patients, decreased renal clearance, peripheral degradation of insulin, and impaired renal gluconeogenesis are all predisposed to the occurrence of hypoglycemia [7].

Meglitinides are short-acting anti-diabetic agents, with a half-life of about one hour, and thus have valuable roles in lowering postprandial hyperglycemia and reducing the danger of hypoglycemia. The main branded drugs in this class are repaglinide and nateglinide. Both repaglinide and nateglinide are metabolized in the liver, and $<10 \%$ of repaglinide and most of nateglinide are renally excreted $[8,9]$. In clinical practice, meglitinides possess similar potency to metformin and could be an alternative where side effects of metformin are intolerable or where metformin is contraindicated [10], such as advanced CKD. Repaglinide can accumulate in patients with advanced renal dysfunction (eGFR $<30 \mathrm{~mL} / \mathrm{min} / 1.73 \mathrm{~m} 2$ ) without a significant increase in hypoglycemia in a small clinical study [11]. Another small-scale study reported that repaglinide was safe and well tolerated in terms of pharmacokinetics and the incidence of hypoglycemia in subjects with varying degrees of renal dysfunction [12]. A metabolite of nateglinide, that has a modest hypoglycemic effect, accumulates in patients with CKD [13].

Experience with the use of meglitinides in advanced CKD is as yet limited; nevertheless, the safety of meglitinides is of particular interest because many advanced CKD patients have been treated with meglitinides for glycemic control in real life [14, 15]. The aim of this study was to examine the risks of meglitinideassociated hypoglycemia and mortality in patients with advanced CKD.

\section{MATERIALS AND METHODS}

\section{Data source}

This population-based cohort study used data retrieved from Taiwan's National Health Insurance (NHI) Research Database, which is one of the largest databases in the world and has been used extensively in various epidemiologic studies [16-19]. The NHI covers almost all 23.7 million people in Taiwan and contains comprehensive healthcare information regarding outpatient visits, hospital admissions, disease profiles, prescriptions, interventional procedures, and vital statuses. All diagnoses are based on the codes of the International Classification of Diseases, 9th Revision (ICD-9).

As all personal information is de-identified in the NHI Research Database, informed consent was waived and this study was exempt from a full ethical review by the institutional review board of the National Taiwan University Hospital (201212021RINC).

\section{Study population}

This study retrospectively included patients aged $\leqq$ 20 years who had diagnosis codes for diabetes mellitus and CKD and received erythropoiesis-stimulating agent (ESA) treatment from January 1, 2000 to December 31, 2010. According to the NHI regulations, ESA can only be prescribed in anemic advanced CKD patients who have a hematocrit level of $\leqq 28 \%$ and a serum creatinine level of $>6 \mathrm{mg} / \mathrm{dL}$ (equivalent to an estimated GFR of $<15$ $\mathrm{ml} / \mathrm{min} / 1.73 \mathrm{~m}^{2}$ ) with the aim of maintaining a hematocrit level of $33-36 \%$. We only included advanced CKD patients who were fresh users of meglitinides and who had no episode of hypoglycemia within one year prior to the first prescription of ESA. Patients who had been treated with dialysis (identified by procedure codes) or received renal transplantation before ESA and those who did not survive 90 days after the first ESA therapy were excluded.

The baseline comorbidities, including diabetes and $\mathrm{CKD}$, were identified from at least one inpatient claim or three outpatient visits within one year preceding the first ESA treatment. This identification approach has been validated with good predictive power [20-22]. The Charlson comorbidity index was calculated by weighing baseline comorbidities [23].

\section{Outcome measures}

The primary outcome was hypoglycemia (ICD-9 codes: $251.2 \mathrm{x}$ ), and the secondary outcome was longterm all-cause mortality. Each patient was followed from the date of the first ESA prescription to the date of the 
hypoglycemic episode, and censored at either death or the end of the study (December 31, 2011), whichever occurred first.

\section{Exposure assessment}

We designed a cohort consisting of fresh users of nateglinide (A10BX03) or repaglinide (A10BX02) after the first dose of ESA, and meglitinide nonusers (defined as one year before enrolling in the study, patients didn't have a history prescription of meglitinides) ). Because studies directly comparing repaglinide and nateglinide are limited, [24-26] in this article we have used the term "meglitindes", which encompass repaglinide and nateglinide, for the analysis.

Fresh users and nonusers of meglitinides were matched at a 1:1 ratio by propensity scoring, with an attempt to make an unbiased estimate of all the confounders predicting meglitinide prescription (Figure 1). After the first dose of ESA, the use of other antidiabetic agents including sulfonylureas, thiazolidinediones (TZD), dipeptidyl peptidase-4 (DPP-4) inhibitors, and insulin was also recorded. Metformin is not included because it is contraindicated in CKD patients due to the risk of lactic acidosis. Frequency of hemoglobin A1c (HBA1c) measurement within 30 days prior to the event of hypoglycemia or death were also identified. The measurements of HBA1c (09006C) were totally copayed by national health insurance system.

\section{Statistical analysis}

Continuous variables are presented as mean \pm standard deviation (SD) or median as appropriate; discrete variables are described as counts and percentages. Independent $t$-tests were used to compare continuous variables and chi-square tests for categorical ones.

Baseline comorbid conditions (listed in Table 1) were inputted into a non-parsimonious multivariable logistic regression model to predict the prescription of meglitinides. The predicted probability derived from the estimated equation was the propensity score for each individual.

Because all anti-diabetic agents carry the risk of drug-related hypoglycemia and mortality, we evaluated the risk factors of hypoglycemia and death using Cox proportional hazards models $[22,27]$ with all anti-diabetic agents as well as end-stage renal disease (ESRD) as timedependent covariates to account for their impacts. In these models, we defined the use of certain anti-diabetic agents as at least one prescription within 30 days prior to the event of hypoglycemia or death. Time-dependent analytical methods have been shown to avoid immortal time bias in observational cohort studies [28, 29]. Variable selection for Cox regression hazards modeling was performed using stepwise multiple regression, with a $p$-to-enter and $p$-to-leave both equal to 0.15 [30]. The final results of multivariate analyses were summarized by hazard ratio (HR) and 95\% confidence intervals (CI).

After adjustment for comorbidities, we also conducted an adjusted comparison of risks of meglitinideassociated hypoglycemia among patient subgroups stratified by the status of liver disease and concomitant use of other anti-diabetic agents.

To evaluate the effect of age on the risk of hypoglycemia, we adopted a generalized additive model (GAM) with adjustment for baseline comorbidities and the status of anti-diabetic agent use. This method grants adjustment for possible nonlinear effects of continuous variables [31-33]. The result was shown as a function curve with values of the log odds ratio and was centered to have an average of zero over the range of the data. The approximate point-wise $95 \% \mathrm{CI}$ was also depicted.

All analyses were carried out using $\mathrm{R}$ software, version 3.1.2 (Free Software Foundation, Inc., Boston, MA, U.S.A.). A two-sided $p$ value $<0.05$ was considered significant.

\section{RESULTS}

\section{Patient characteristics}

Matching of the 2,793 fresh meglitinide users with the same number of meglitinide nonusers as controls was performed using propensity scores (Figure 1). The average age was 63 years, $50 \%$ were male, and the Charlson comorbidity index was around 3.5 (Table 1). The proportion of patients with hypertension, cardiovascular disease, moderate or severe liver disease and malignancy were similar in the two groups.

All kinds of anti-diabetic agents were prescribed more frequently in fresh meglitinide users compared to nonusers. In the univariate analysis, the prevalence of hypoglycemia was higher among meglitinide nonusers than among fresh users $(p<0.001)$, but the mortality was not significantly different between the two groups.

\section{Risk factors for hypoglycemia}

In the multivariate time-dependent Cox regression analysis (Table 2), meglitinide, as well as sulfonylurea and insulin, increased the risk of hypoglycemia after risk adjustments (all $p<0.001$ ). Age and male gender also slightly increased the hypoglycemic risk, while subsequent ESRD did not. In addition, more frequently measurments of HBA1c, in term of disease status could predict to hypoglycemic events.

This model exhibited modest discrimination with a $\mathrm{c}$ statistic of 0.65 and an adjusted R2 of 0.04 . Furthermore, 
Table 1: Clinical characteristics and outcomes in patients with advanced CKD, categorized by fresh users and nonusers of meglitinides

\begin{tabular}{|l|l|l|l|}
\hline & \multicolumn{1}{|c|}{$\begin{array}{c}\text { Meglitinide nonusers } \\
(\boldsymbol{n = 2 7 9 3 )}\end{array}$} & $\begin{array}{c}\text { Meglitinide fresh users } \\
(\boldsymbol{n}=\mathbf{2 7 9 3})\end{array}$ & $\boldsymbol{p}$-value \\
\hline Male gender & $1422(50.9 \%)$ & $1432(51.3 \%)$ & 0.81 \\
\hline Age (year) & $63.28 \pm 11.65$ & $63.53 \pm 11.04$ & 0.83 \\
\hline Baseline comorbidities & $3.51 \pm 1.42$ & $3.48 \pm 1.50$ & 0.60 \\
\hline Charlson comorbidity index & $69(2.5 \%)$ & $55(2.0 \%)$ & 0.24 \\
\hline Myocardial infarction & $399(14.3 \%)$ & $398(14.2 \%)$ & 0.99 \\
\hline Congestive heart failure & $32(1.1 \%)$ & $27(1.0 \%)$ & 0.60 \\
\hline Peripheral vascular disease & $175(6.3 \%)$ & $167(6.0 \%)$ & 0.70 \\
\hline Cerebrovascular disease & $22(0.8 \%)$ & $21(0.8 \%)$ & 0.99 \\
\hline Dementia & $157(5.6 \%)$ & $165(5.9 \%)$ & 0.69 \\
\hline COPD & $15(0.5 \%)$ & $14(0.5 \%)$ & 0.99 \\
\hline Rheumatologic disease & $378(13.5 \%)$ & $377(13.5 \%)$ & 0.99 \\
\hline Peptic ulcer & $16(0.6 \%)$ & $11(0.4 \%)$ & 0.44 \\
\hline Hemiplegia & $64(2.3 \%)$ & $68(2.4 \%)$ & 0.79 \\
\hline Malignancy & $109(3.9 \%)$ & $132(4.7 \%)$ & 0.15 \\
\hline Moderate or severe liver disease & $2115(75.7 \%)$ & $2109(75.5 \%)$ & 0.88 \\
\hline Hypertension & \multicolumn{3}{|l|}{} \\
\hline Anti-diabetic agents & $1239(44.4 \%)$ & $1931(69.1 \%)$ & $<0.001$ \\
\hline Sulfonylurea & $232(8.3 \%)$ & $554(19.8 \%)$ & $<0.001$ \\
\hline DPP-4 inhibitor & $393(14.1 \%)$ & $836(29.9 \%)$ & $<0.001$ \\
\hline Thiazolidinedione (TZD) & $2189(78.4 \%)$ & $2481(88.8 \%)$ & $<0.001$ \\
\hline Insulin & & & \\
\hline Outcomes & $361(12.9 \%)$ & $237(8.5 \%)$ & $<0.001$ \\
\hline Hypoglycemia & $1242(44.5 \%)$ & $1177(42.1 \%)$ & 0.084 \\
\hline Mortality &
\end{tabular}

Abbreviations: COPD, chronic obstructive pulmonary disease; DPP-4 inhibitor, dipeptidyl peptidase-4 inhibitor

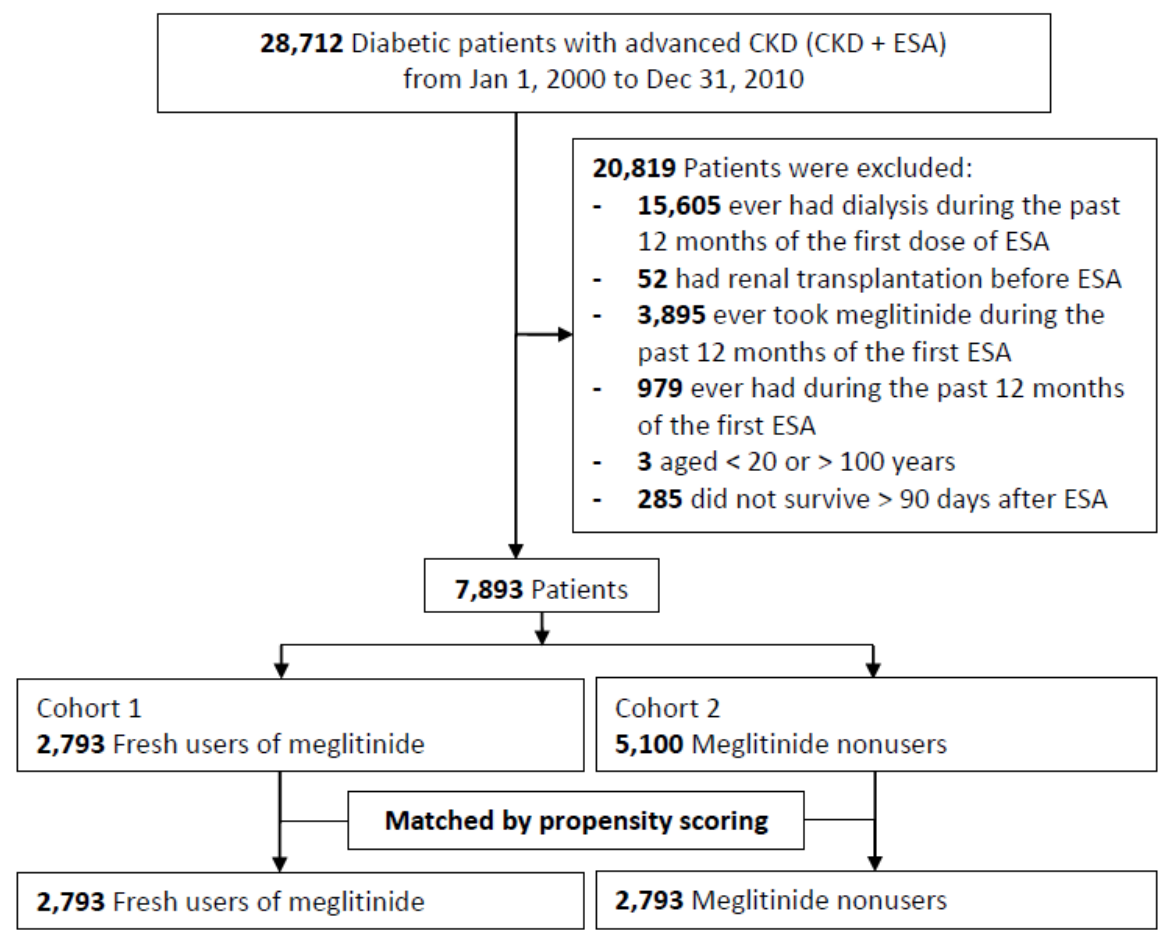

Figure 1: Detailed flowchart for patient enrollment. 
Table 2: Risk factors of new onset hypoglycemia by time varying cox regression model ${ }^{\#}$

\begin{tabular}{|c|c|c|}
\hline & Hazard Ratio (95\% confidence interval) & $\boldsymbol{p}$-value \\
\hline Age (per year) & $1.01(1.00-1.02)$ & 0.001 \\
Male gender & $1.17(1.00-1.38)$ & 0.053 \\
Meglitinide* & $1.85(1.50-2.29)$ & $<0.001$ \\
Sulfonylurea* & $1.90(1.58-2.29)$ & $<0.001$ \\
Insulin* & $2.08(1.76-2.45)$ & $<0.001$ \\
ESRD* & $0.55(0.44-0.69)$ & $<0.001$ \\
Frequency of HbA1c measurements* & $1.17(1.10-1.24)$ & $<0.001$ \\
\hline
\end{tabular}

Abbreviations: ESRD: End-stage renal disease, HbA1c: Hemoglobin A1c

*, adjusted as time varying model.

\#, time varying cox regression model, ajudsted with age, gender, comorbidities, antidiabetic agents and Frequency of HBA1c measurement. Table 3: Risk factors of all-cause mortality

the hypoglycemic risk from meglitinides was consistently elevated across the subgroups stratified by the status of concomitant use of other anti-diabetic agents (Figure 2).

We then evaluated the relationship between age and the risk of hypoglycemia using GAM. The function curve was non-linear and there was an insignificant trend towards increased hypoglycemic risk in patients aged $>62$ and $\leq 33$ years (Figure 3 ).

\section{The risk of hypoglycemia on meglitinide from the other agents}

We further do the interacting effect of meglitinide and other antidiabetic agents on hypoglycemia. The hypoglycemic effect of meglitinide was consistent among patient subgroups stratified by the status of concomitant use of other antidiabetic agents. However, meglitinide with insulin will increase the risk of hypoglycemia. ( $p$ $=0.018$ ) (Table 4). In addition, most P450 inhibitors will not augment the effect of meglitinide in regarding subsequent hypoglycemi

\section{Risk factors for all-cause mortality}

Table 3 shows the clinical predictors of death after applying the time-varying Cox proportional hazards model. While DPP-4 inhibitor and time-varying ESRD predicted a lower risk of death, factors such as
Adjusted HR $[95 \% \mathrm{CI}]$

DPP-4 inhibitor
Yes
No
TZD
Yes *
No
Sulfonylurea
Yes
No
Insulin
Yes
No
Moderate or severe liver disease
Yes*
No

$2.34[1.25,4.39]$

$1.82[1.45,2.28]$

$2.02[1.59,2.56]$

$1.46[1.11,1.91]$

$2.42[1.73,3.39]$

$1.78[1.40,2.25]$

$1.76[1.10,2.80]$

$1.79[1.45,2.21]$
No. of Event / No. at Risk

Meglitinide (+) Meglitinide (-)

$30 / 554$

$207 / 2239$

$12 / 232$

$349 / 2561$

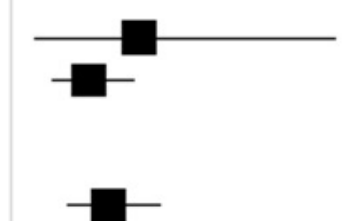

$169 / 1957$

$312 / 2400$

$164 / 1931$

$187 / 1239$

$174 / 1554$

$201 / 2481$

$36 / 312$

$255 / 2189$

$106 / 604$

$227 / 2661$

$349 / 2684$

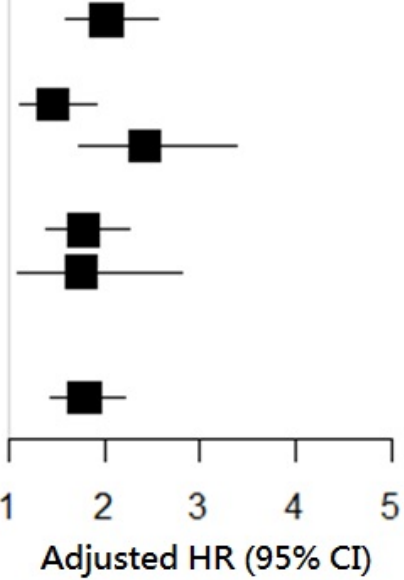

Figure 2: Hazard ratio for fresh use (versus nonuse) of meglitinides on the occurrence of hypoglycemia, stratified according to the statuses of concomitant use of other anti-diabetic agents, and of prior liver disease.* Data not shown due to insignificant hazard ratios. 
Table 3: Risk factors of all-cause mortality

\begin{tabular}{|l|c|c|}
\hline & Hazard Ratio (95\% confidence interval) & $\boldsymbol{p}$-value \\
\hline Age (per year) & $1.03(1.03-1.04)$ & $<0.001$ \\
Male gender & $1.11(1.02-1.20)$ & 0.011 \\
Hypoglycemia & $13.35(12.29-14.50)$ & $<0.001$ \\
Meglitinides & $0.93(0.82-1.06)$ & 0.300 \\
Insulin & $2.22(2.04-2.40)$ & $<0.001$ \\
DPP-4 inhibitor & $0.58(0.42-0.80)$ & 0.001 \\
End-stage renal disease (ESRD) & $0.60(0.54-0.67)$ & $<0.001$ \\
Congestive heart failure & $1.47(1.32-1.64)$ & $<0.001$ \\
Myocardial infarction & $1.54(1.21-1.96)$ & $<0.001$ \\
Moderate or severe liver disease & $1.52(1.27-1.82)$ & 0.001 \\
Cerebrovascular disease & $1.17(1.01-1.36)$ & 0.004 \\
Hemiplegia & $2.00(1.24-3.21)$ & 0.017 \\
Rheumatologic disease & $2.00(1.13-3.54)$ & 0.041 \\
Hypertension & $1.11(1.00-1.23)$ & \\
\hline
\end{tabular}

Abbreviation: DPP-4 inhibitor, dipeptidyl peptidase-4 inhibitor

Table 4: The interaction of medications of interesting to predict new onset hypoglycemia after adding final model*

\begin{tabular}{|c|c|c|c|}
\hline Co-admission & Interaction with Meglitinide & HR $(95 \%$ CI $)$ & $p$ \\
\hline \multicolumn{4}{|c|}{ Antihyperglycemic agents } \\
\hline DPP4 inhibitor & 1.14 & $0.55-2.34$ & 0.728 \\
\hline TZD & 0.64 & $0.05-2.54$ & 0.224 \\
\hline Sulfonylurea & 0.94 & $0.55-1.59$ & 0.808 \\
\hline Insulin & 1.69 & $1.40-1.98$ & 0.018 \\
\hline \multicolumn{4}{|l|}{ P450 Inhibitors } \\
\hline \multicolumn{4}{|l|}{ CYF1A2 } \\
\hline Ciprofloxacin & 0.35 & $0.05-2.54$ & 0.301 \\
\hline Amiodarone & 1.86 & $0.81-4.25$ & 0.140 \\
\hline Cimentidine & 0.81 & $0.40-1.68$ & 0.578 \\
\hline \multicolumn{4}{|l|}{ CYP2C9 } \\
\hline Fluconazole & 0.78 & $0.11-5.62$ & 0.806 \\
\hline \multicolumn{4}{|l|}{ CYP2C19 } \\
\hline Omeprazole & 1.18 & $0.61-2.27$ & 0.619 \\
\hline \multicolumn{4}{|l|}{ CYP2A4/5 } \\
\hline Clarithromycin & 3.20 & $0.79-13.03$ & 0.104 \\
\hline Erythromycin & 0.56 & $0.08-4.04$ & 0.568 \\
\hline Ketoconazole & 1.03 & $0.14-7.41$ & 0.975 \\
\hline
\end{tabular}

age, male gender, insulin use, hypoglycemia and other baseline comorbidities all predicted mortality. The use of meglitinides had no significant impact on survival ( $c$ statistic 0.82 , adjusted R2 0.55).

\section{DISCUSSION}

This nationwide study, which included a total of 5,586 advanced CKD patients, demonstrated that fresh users of meglitinides had a 1.9-fold greater risk of developing hypoglycemia than meglitinide nonusers. Although short-acting meglitinides are supposed to offer the advantage of having lower incidence of hypoglycemia, our results showed that the magnitude of the risk in advanced CKD patients was comparable to that of sulfonylurea or insulin.
Our advanced diabetic CKD cohort demonstrated an overall prevalence of hypoglycemia (proportion of people) at $10.7 \%$, much higher than that of the overall diabetic population, ranging from $2.4 \%$ to $6.3 \%$ in two large population-based studies $[34,35]$. In the general population, the addition of meglitinide versus placebo to other anti-diabetic agents produced a clinically significant reduction in glycosylated hemoglobin and more frequent but mild hypoglycemia [10]. The main findings for advanced CKD furthermore suggested that meglitinides consistently increased the hypoglycemic risk whether they were or were not combined with other anti-diabetic agents (Figure 2).

Meglitinide-associated hypoglycemia in CKD could be attributed to drug- and non-drug-related factors. Renally excreted meglitinides and metabolites accumulate and have a prolonged half-life in CKD. Uremic toxins further 
derange glucose homeostasis and insulin metabolism [9]. While augmented hepatic gluconeogenesiss [36], impaired beta-cell response to glucose, and peripheral insulin resistance [37] all predispose CKD patients to hyperglycemia, counteractive mechanisms such as deficient renal gluconeogenesis, impaired renal insulin clearance and degradation, anorexia and diminished glycogen stores, and deficiency in immediate counterregulatory catecholamine response can render patients as hypoglycemic [7]. The Kidney Disease Outcomes Quality Initiative (KDOQI) guidelines recommend starting nateglinide and repaglinide conservatively at $60 \mathrm{mg}$ and $0.5 \mathrm{mg}$, respectively, taken with meals for patients with CKD stage 4-5 [38], while other reviews recommend avoiding nateglinide use in patients with CKD stage 5 $[9,39]$. Although there are different recommendations, the current body of literature suggests that lower starting doses, prudent monitoring and individualized dose titration are always required to avoid the occurrence of hypoglycemia.

Aging can blunt the autonomic counter-regulatory responses to hypoglycemia and reduces the awareness of low blood glucose condition [40]. Other factors may also contribute to hypoglycemia in the elderly, such as decreased cognition, multiple comorbidities, and polypharmacy [40]. In contrast to previous studies that suggested hypoglycemia is more common in old diabetic patients $[40,41]$, our results showed an insignificant U-shaped pattern between the risk of hypoglycemia and age in patients with diabetes and CKD. Limited evidence also demonstrated that the events suggestive of hypoglycemia by nateglinide or by glyburide were similar in the elderly and elderly subgroup with renal failure compared with the overall population [42]. More studies are needed to evaluate the interaction between age and $\mathrm{CKD}$ in relation to the risk of hypoglycemia.

This study has demonstrated that hypoglycemia, and not meglitinide use, is associated with increased mortality. We showed that meglitinide indirectly could induce long-term mortality rate of by increasing their risk of hypoglycemia. Many antihyperglycemic agents and risk factors will increase the risk of hypoglycemia. The transitive relationship of meglitinide to mortality was taken place by the subsequent hypoglycemia. The concept is in

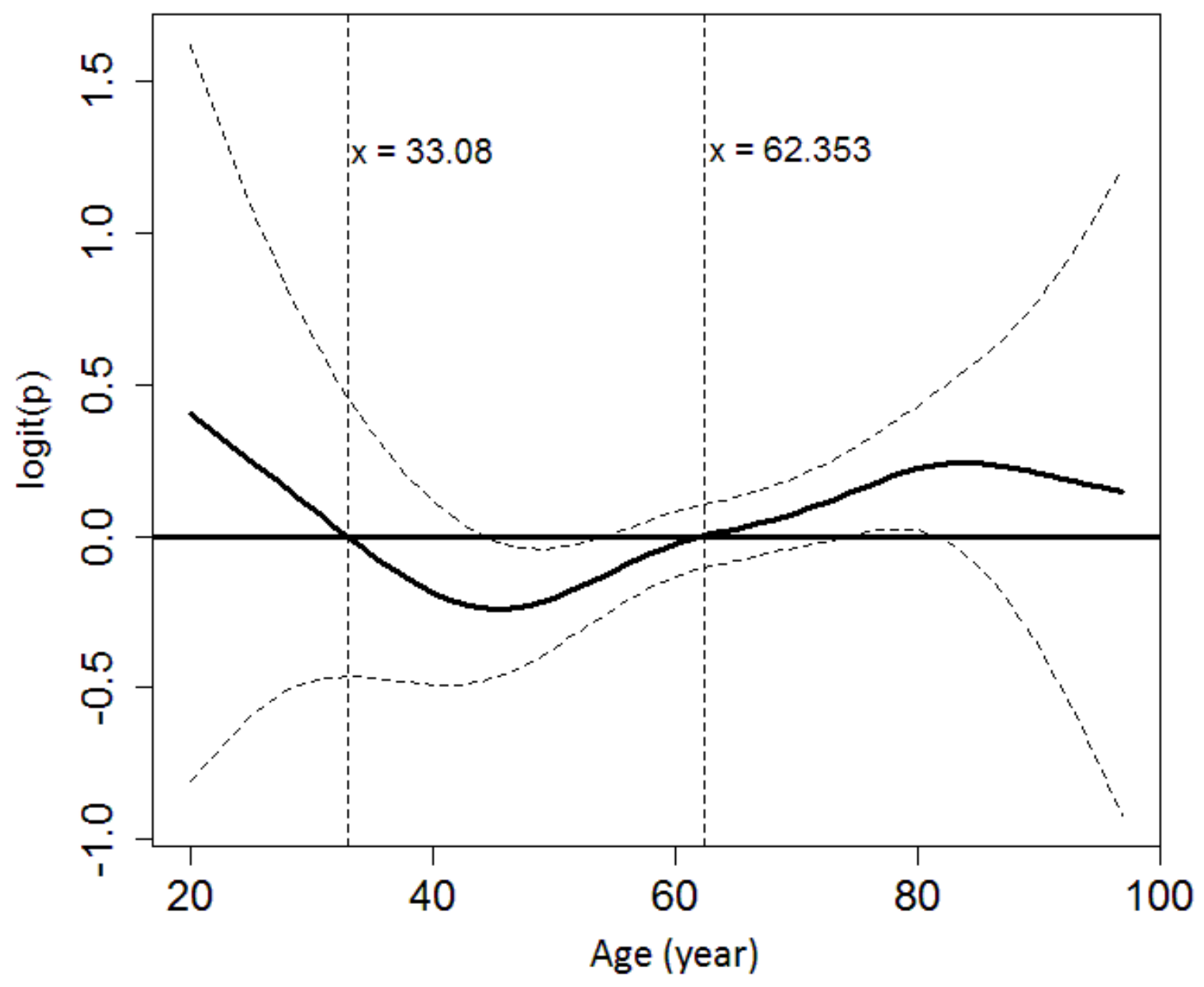

Figure 3: The relationship between age and the probability of developing hypoglycemia using generalized additive modeling and adjusting for gender, end-stage renal disease and the use of anti-diabetic agents. 
line with meglitinide-related hypoglycemia and other antidiabetic agent-related hypoglycemia eventually attributing to cardiovascular events, all-cause hospitalization, and allcause mortality [43]. Hypoglycemia may be associated with augmented sympathetic activity and catecholamine release, leading to confusion, myocardial infarction, and dysrhythmia, which in turn lead to morbidities and mortality.

Our study has a number of limitations. First, the frequency of hypoglycemia might be underestimated. Although the diagnosis codes were regularly scrutinized by the Bureau of NHI and highly accurate, patients with mild or moderate hypoglycemia might be treated at home without seeking medical attention, thereby leading to underreporting of the prevalence of hypoglycemia. Data regarding other factors that might affect the risk of hypoglycemia including the levels of glycosylated hemoglobin, educational status, smoking and alcohol habits, physical activity and body mass index were unavailable from the NHI Research Database. Especially, glycated hemoglobin is tightly associated with risk of hypoglycemia.

However, due to the relatively large sample size, all the errors were likely non-differential and the confounders might not make our results systemically deviated from the truth. Second, our target population of patients with advanced CKD was identified by ICD-9 codes for CKD plus drug codes for ESA. Given that the rate of ESA prescription was $85 \%$ in 2012 in predialysis stage 5 CKD patients according to an internal report of the Taiwan Department of Health, we believe the patients on ESA therapy were representative and constituted the majority of stage 5 CKD patients.

In conclusion, this nationwide cohort study provides evidence that fresh use of meglitinides increases the risk of hypoglycemia in predialysis stage 5 CKD patients. As CKD itself increases the risk of hypoglycemia, our results additionally suggest CKD patients taking shortacting meglitinides still require careful monitoring against hypoglycemia. Furthermore, concomitant use of meglitinide and insulin will increase the hypoglycemic risk.

\section{Authors' contributions}

Pei-Chen $\mathrm{Wu}$ drafted the manuscript. Likwang Chen, Tao-Min Huang, and Che-Hsiung Wu collected the data. Vin-Cent Wu and Chih-Jen Wu provided the original conception and design of the study. Cheng-Jui Lin, ChiFeng Pan, Likwang Chen and Chih-Yang Chen modified the statistical models critically and provided technical and statistical support during the analyses. All the authors interpreted the data, revised the manuscript, and approved the final article.

\section{ACKNOWLEDGMENTS}

The authors would like to thank the staff of the Second Core Lab in the Department of Medical Research in National Taiwan University Hospital for technical assistance. This study was supported by grants from the Taiwan National Science Council (NSC 101-2314-B-002-132-MY3, NSC100-2314-B-002-119, NSC 101-2314-B-002-085-MY3, MOST 104-2314-B-002 -125 -MY3, :MOST105-2325-B-002-025) and the NTUH 105-S3061,VN105-04, 105-P05.Additional support for this work was also provided by the TR15, CAKS National Research Program for Biopharmaceuticals, ROC, Taiwan. The whole draft has been revised by Mr. Rory Connolly. We thank Dr. Likwang Chen who helped us to retrieve the original data from the TNHRI databank and National Science Council. The other funding organization, National Science Council, played no role in the design and conduct of the study, in the collection, management, analysis, and interpretation of the data, and in the preparation, review, and approval of the manuscript. No completing interest was declared. No financial conflict of interest exists.

\section{CONFLICTS OF INTEREST}

The authors declare no conflicts of interest.

\section{REFERENCES}

1. Collins AJ, Foley RN, Chavers B, Gilbertson D, Herzog C, Ishani A, Johansen K, Kasiske BL, Kutner N, Liu J, St Peter W, Guo H, Hu Y, et al. US Renal Data System 2013 Annual Data Report. Am J Kidney Dis. 2014; 63:A7.

2. Patel A, MacMahon S, Chalmers J, Neal B, Billot L, Woodward M, Marre M, Cooper M, Glasziou P, Grobbee D, Hamet P, Harrap S, Heller S, et al. Intensive blood glucose control and vascular outcomes in patients with type 2 diabetes. N Engl J Med. 2008; 358:2560-72.

3. Duckworth W, Abraira C, Moritz T, Reda D, Emanuele N, Reaven PD, Zieve FJ, Marks J, Davis SN, Hayward R, Warren SR, Goldman S, McCarren M, et al. Glucose control and vascular complications in veterans with type 2 diabetes. N Engl J Med. 2009; 360:129-39.

4. Ismail-Beigi F, Craven T, Banerji MA, Basile J, Calles J, Cohen RM, Cuddihy R, Cushman WC, Genuth S, Grimm RH Jr, Hamilton BP, Hoogwerf B, Karl D, et al. Effect of intensive treatment of hyperglycaemia on microvascular outcomes in type 2 diabetes: an analysis of the ACCORD randomised trial. Lancet. 2010; 376:419-30.

5. Bell DS, Patil HR, O'Keefe JH. Divergent effects of various diabetes drugs on cardiovascular prognosis. Rev Cardiovasc Med. 2013; 14:e107-22.

6. Williams ME, Garg R. Glycemic management in ESRD and earlier stages of CKD. Am J Kidney Dis. 2014; 63:S22-38.

7. Moen MF, Zhan M, Hsu VD, Walker LD, Einhorn LM, 
Seliger SL, Fink JC. Frequency of hypoglycemia and its significance in chronic kidney disease. Clin J Am Soc Nephrol. 2009; 4:1121-27.

8. Snyder RW, Berns JS. Use of insulin and oral hypoglycemic medications in patients with diabetes mellitus and advanced kidney disease. Semin Dial. 2004; 17:365-70.

9. Nogueira C, Souto SB, Vinha E, Braga DC, Carvalho D. Oral glucose lowering drugs in type 2 diabetic patients with chronic kidney disease. Hormones (Athens). 2013; 12:48394.

10. Black C, Donnelly P, McIntyre L, Royle PL, Shepherd JP, Thomas S. Meglitinide analogues for type 2 diabetes mellitus. Cochrane Database Syst Rev. 2007CD004654.

11. Schumacher S, Abbasi I, Weise D, Hatorp V, Sattler K, Sieber J, Hasslacher C. Single- and multiple-dose pharmacokinetics of repaglinide in patients with type 2 diabetes and renal impairment. Eur J Clin Pharmacol. 2001; 57:147-52.

12. Marbury TC, Ruckle JL, Hatorp V, Andersen MP, Nielsen KK, Huang WC, Strange P. Pharmacokinetics of repaglinide in subjects with renal impairment. Clin Pharmacol Ther. 2000; 67:7-15.

13. Inoue $\mathrm{T}$, Shibahara $\mathrm{N}$, Miyagawa $\mathrm{K}$, Itahana R, Izumi M, Nakanishi T, Takamitsu Y. Pharmacokinetics of nateglinide and its metabolites in subjects with type 2 diabetes mellitus and renal failure. Clin Nephrol. 2003; 60:90-95.

14. Penfornis A, Blicklé JF, Fiquet B, Quéré S, Dejager S. How are patients with type 2 diabetes and renal disease monitored and managed? Insights from the observational OREDIA study. Vasc Health Risk Manag. 2014; 10:34152.

15. Patel PA, Liang L, Khazanie P, Hammill B, Fonarow G, Heidenreich P, Yancy C, Bhatt D, Curtis L, Hernandez A. Anti-hyperglycemic medication use among medicare beneficiaries with heart failure, diabetes, and chronic kidney disease. J Am Coll Cardiol. 2015; 65:61024-25.

16. $\mathrm{Wu} \mathrm{PC}, \mathrm{Wu} \mathrm{CJ}$, Lin $\mathrm{CJ}, \mathrm{Wu} \mathrm{VC}$, National Taiwan University Study Group on Acute Renal Failure Group. Long-term risk of upper gastrointestinal hemorrhage after advanced AKI. Clin J Am Soc Nephrol. 2015; 10:353-62.

17. Wu VC, Wu CH, Huang TM, Wang CY, Lai CF, Shiao CC, Chang CH, Lin SL, Chen YY, Chen YM, Chu TS, Chiang $\mathrm{WC}, \mathrm{Wu} \mathrm{KD}$, et al. Long-term risk of coronary events after AKI. J Am Soc Nephrol. 2014; 25:595-605.

18. Wang WJ, Chao CT, Huang YC, Wang CY, Chang CH, Huang TM, Lai CF, Huang HY, Shiao CC, Chu TS, Chen YM, Wu VC, Ko WJ, et al. The impact of acute kidney injury with temporary dialysis on the risk of fracture. Journal of bone and mineral research. 2013; 29:676-684.

19. Wu VC, Wu PC, Wu CH, Huang TM, Chang CH, Tsai PR, Ko WJ, Chen L, Wang CY, Chu TS, Wu KD, National Taiwan University Study Group on Acute Renal Failure (NSARF) Group. The impact of acute kidney injury on the long-term risk of stroke. J Am Heart Assoc. 2014; 3:e000933.

20. Wu VC, Hu YH, Wu CH, Kao CC, Wang CY, Yang WS, Lee HH, Chang YS, Lin YH, Wang SM, Chen L, Wu KD, TAIPAI Study Group. Administrative data on diagnosis and mineralocorticoid receptor antagonist prescription identified patients with primary aldosteronism in Taiwan. J Clin Epidemiol. 2014; 67:1139-49.

21. Cheng CL, Kao YH, Lin SJ, Lee CH, Lai ML. Validation of the National Health Insurance Research Database with ischemic stroke cases in Taiwan. Pharmacoepidemiol Drug Saf. 2011; 20:236-42.

22. Wang WJ, Chao CT, Huang YC, Wang CY, Chang $\mathrm{CH}$, Huang TM, Lai CF, Huang HY, Shiao CC, Chu TS, Chen $\mathrm{YM}, \mathrm{Wu} \mathrm{VC}, \mathrm{Ko} \mathrm{WJ}$, et al. The impact of acute kidney injury with temporary dialysis on the risk of fracture. $\mathrm{J}$ Bone Miner Res. 2014; 29:676-84.

23. Charlson ME, Pompei P, Ales KL, MacKenzie CR. A new method of classifying prognostic comorbidity in longitudinal studies: development and validation. J Chronic Dis. 1987 ; 40:373-83.

24. Raskin P, Klaff L, McGill J, South SA, Hollander P, Khutoryansky N, Hale PM. Repaglinide vs. Nateglinide Metformin Combination Study Group. Efficacy and safety of combination therapy: repaglinide plus metformin versus nateglinide plus metformin. Diabetes Care. 2003; 26:206368.

25. Rosenstock J, Hassman DR, Madder RD, Brazinsky SA, Farrell J, Khutoryansky N, Hale PM. Repaglinide Versus Nateglinide Comparison Study Group. Repaglinide versus nateglinide monotherapy: a randomized, multicenter study. Diabetes Care. 2004; 27:1265-70.

26. Guardado-Mendoza R, Prioletta A, Jiménez-Ceja LM, Sosale A, Folli F. The role of nateglinide and repaglinide, derivatives of meglitinide, in the treatment of type 2 diabetes mellitus. Arch Med Sci. 2013; 9:936-43.

27. Lai TS, Wang CY, Pan SC, Huang TM, Lin MC, Lai CF, $\mathrm{Wu} \mathrm{CH}, \mathrm{Wu} \mathrm{VC}$, Chien KL, National Taiwan University Hospital Study Group on Acute Renal Failure (NSARF). Risk of developing severe sepsis after acute kidney injury: a population-based cohort study. Crit Care. 2013; 17:R231.

28. Shariff SZ, Cuerden MS, Jain AK, Garg AX. The secret of immortal time bias in epidemiologic studies. J Am Soc Nephrol. 2008; 19:841-43.

29. Shintani AK, Girard TD, Eden SK, Arbogast PG, Moons $\mathrm{KG}$, Ely EW. Immortal time bias in critical care research: application of time-varying Cox regression for observational cohort studies. Crit Care Med. 2009; 37:2939-45.

30. Wu VC, Huang TM, Lai CF, Shiao CC, Lin YF, Chu TS, Wu PC, Chao CT, Wang JY, Kao TW, Young GH, Tsai $\mathrm{PR}$, Tsai HB, et al. Acute-on-chronic kidney injury at hospital discharge is associated with long-term dialysis and mortality. Kidney Int. 2011; 80:1222-30.

31. Woo MJ, Reiter JP, Karr AF. Estimation of propensity scores using generalized additive models. Stat Med. 2008; 
27:3805-16.

32. $\mathrm{Wu} \mathrm{VC}$, Lo SC, Chen YL, Huang PH, Tsai CT, Liang CJ, Kuo CC, Kuo YS, Lee BC, Wu EL, Lin YH, Sun YY, Lin SL, et al. Endothelial progenitor cells in primary aldosteronism: a biomarker of severity for aldosterone vasculopathy and prognosis. J Clin Endocrinol Metab. 2011; 96:3175-83.

33. Shu $\mathrm{KH}$, Wang $\mathrm{CH}$, Wu CH, Huang TM, Wu PC, Lai $\mathrm{CH}$, Tseng LJ, Tsai PR, Connolly R, Wu VC. Urinary $\pi$-glutathione S-transferase Predicts Advanced Acute Kidney Injury Following Cardiovascular Surgery. Sci Rep. 2016; 6:26335.

34. Hsu PF, Sung SH, Cheng HM, Yeh JS, Liu WL, Chan WL, Chen $\mathrm{CH}$, Chou P, Chuang SY. Association of clinical symptomatic hypoglycemia with cardiovascular events and total mortality in type 2 diabetes: a nationwide populationbased study. Diabetes Care. 2013; 36:894-900.

35. Edridge CL, Dunkley AJ, Bodicoat DH, Rose TC, Gray LJ, Davies MJ, Khunti K. Prevalence and Incidence of Hypoglycaemia in 532,542 People with Type 2 Diabetes on Oral Therapies and Insulin: A Systematic Review and Meta-Analysis of Population Based Studies. PLoS One. 2015; 10:e126427.

36. Chapagain A, Caton PW, Kieswich J, Andrikopoulos P, Nayuni N, Long JH, Harwood SM, Webster SP, Raftery MJ, Thiemermann C, Walker BR, Seckl JR, Corder R, Yaqoob MM. Elevated hepatic 11 $\beta$-hydroxysteroid dehydrogenase type 1 induces insulin resistance in uremia. Proc Natl Acad Sci USA. 2014; 111:3817-22.
37. Leyking S, Fliser D. Insulin resistance in CKD. Clin J Am Soc Nephrol. 2014; 9:638-40.

38. Foundation NK, National Kidney Foundation. KDOQI Clinical Practice Guideline for Diabetes and CKD: 2012 Update. Am J Kidney Dis. 2012; 60:850-86.

39. Abe M, Okada K, Soma M. Antidiabetic agents in patients with chronic kidney disease and end-stage renal disease on dialysis: metabolism and clinical practice. Curr Drug Metab. 2011; 12:57-69.

40. Bramlage P, Gitt AK, Binz C, Krekler M, Deeg E, Tschöpe D. Oral antidiabetic treatment in type-2 diabetes in the elderly: balancing the need for glucose control and the risk of hypoglycemia. Cardiovasc Diabetol. 2012; 11:122.

41. Abdelhafiz AH, Rodríguez-Mañas L, Morley JE, Sinclair AJ. Hypoglycemia in older people - a less well recognized risk factor for frailty. Aging Dis. 2015; 6:156-67.

42. Del Prato S, Heine RJ, Keilson L, Guitard C, Shen SG, Emmons RP. Treatment of patients over 64 years of age with type 2 diabetes: experience from nateglinide pooled database retrospective analysis. Diabetes Care. 2003; 26:2075-80.

43. Desouza CV, Bolli GB, Fonseca V. Hypoglycemia, diabetes, and cardiovascular events. Diabetes Care. 2010; 33:1389-94. 